\title{
Absence of Gamma Interferon and Interleukin 2 Production during Active Visceral Leishmaniasis
}

\author{
Edgar M. Carvalho and Roberto Badaró \\ Immunology Division, Federal University of Bahia Hospital, Salvador, Bahia, Brazil
}

Steven G. Reed, Thomas C. Jones, and Warren D. Johnson, Jr.

Cornell University Medical College, Division of International Medicine, New York 10021

\begin{abstract}
The lymphocytes from eight patients with active visceral leishmaniasis (VL), a disease associated with marked immunologic dysfunction, were examined for ability to produce interleukin 2 (IL-2) and gamma interferon during in vitro cultivation. It was found that both IL-2 and gamma interferon production, in response to leishmania antigen, was absent during the active disease, but was restored after successful chemotherapy. Untreated VL patients produced IL-2 and gamma interferon when stimulated with phytohemagglutinin (PHA). Six patients with either active cutaneous or mucosal leishmaniasis, a disease not associated with immunosuppression, showed high levels of gamma interferon in response to leishmania antigen and PHA. Since IL-2 and gamma interferon have been shown to have important roles in the immune response and in the killing of leishmania, their absence may represent a key defect in the immune response in VL.
\end{abstract}

\section{Introduction}

Since early observations of the protozoan disease visceral leishmaniasis (VL), ${ }^{1}$ it has been clear that immunologic dysfunction is an important aspect of the illness. The immunologic defects that have been described include the following: $(a)$ absence of antigen-specific intradermal skin test responses $(1,2)$; $(b)$ depressed lymphocyte transformation to leishmania antigen (3); $(c)$ presence of serum suppressor factors $(4) ;(d)$ presence of circulating immune complexes and polyclonal hypergammaglobulinemia (5); and (e) increased susceptibility to various infections (6). In order to focus more specifically on the immunologic defects in leishmaniasis and to determine the possible mechanisms of pathogenesis of Leishmania donovani infection, we examined the ability of lymphocytes from patients with active VL to produce gamma interferon and interleukin 2 (IL-2). In addition, the lymphocyte response to leishmania antigen and the numbers of $T$ cell subsets were determined.

Address reprint requests to Dr. E. M. Carvalho, Hospital Prof. Edgard Santos, Rua Jaão das Botas, s/n-Canela, 40000 Salvador, Bahia, Brasil. Received for publication 9 May 1985.

1. Abbreviations used in this paper: AIDS, acquired immune deficiency syndrome; Con A, concanavalin A; IL-2, interleukin 2; VL, visceral leishmaniasis.

J. Clin. Invest.

(c) The American Society for Clinical Investigation, Inc. $0021-9738 / 85 / 12 / 2066 / 04 \$ 1.00$

Volume 76, December 1985, 2066-2069

\section{Methods}

Patients were seen in either the Federal University Hospital in Salvador, Bahia, Brazil, or in an area (Jacobina, Bahia, Brazil) endemic for VL (7). They presented with characteristic signs and symptoms of active VL, including fever, hepatosplenomegaly, anemia, leukopenia, and hyperglobulinemia. The diagnosis was confirmed by identification of leishmania in Giemsa-stained bone marrow aspirates. Control subjects included three cutaneous and three mucosal leishmaniasis patients with intact immunological responses to leishmania antigens, and four uninfected persons from areas that are not endemic for leishmaniasis.

Antigen preparation. An isolate of Leishmania donovani chagasi was obtained from a bone marrow aspirate of a patient in the Jacobina area. The parasite was characterized by its growth in culture media and its pattern of infection in hamsters, by isoenzyme analysis, and by kinetoplast DNA restriction enzyme analysis (courtesy of Dr. Peter Jackson, Walter Reed Army Institute of Research, Washington, DC). Promastigotes of this $L$. $d$. chagasi isolate ("Risea") were grown in RPMI 1640 (Gibco Laboratories, Grand Island, NY) supplemented with essential and nonessential amino acids, sodium pyruvate, Hepes buffer, hemin $(4 \mu \mathrm{g} / \mathrm{ml})$, and $20 \%$ screened, heat-inactivated fetal bovine serum. Parasites were recovered in stationary growth phase, washed five times in phosphatebuffered saline ( $\mathrm{pH} 7.2$ ), supplemented with $2 \%$ fetal bovine serum, and resuspended in Millipore-filtered deionized water (Millipore/Continental Water Systems, Bedford, MA). They were subjected to 12 cycles of alternate freezing (liquid nitrogen) and thawing $\left(37^{\circ} \mathrm{C}\right.$ water bath) and centrifuged at $20,000 \mathrm{~g}$ for $30 \mathrm{~min}$ (7). The supernatant was collected, Millipore-filtered, and analysed for protein content with the Lowry colorimetric assay (8).

Lymphocyte transformation. Peripheral blood mononuclear cells were obtained by centrifugation of heparinized venous blood over a density gradient using lymphocyte separation media (Bionetics Laboratory, Kensington, MD). After washing the mononuclear cells in RPMI 1640, they were adjusted to a concentration of $10^{6} / \mathrm{ml}$ in media containing $15 \%$ heat-inactivated normal human serum. Aliquots containing $2 \times 10^{5}$ cells were plated in triplicate in 96-well microtiter plates (Linbro Chemical Co., New Haven, CT) and stimulated with leishmania antigen $(5 \mu \mathrm{g} / \mathrm{ml})$. After $5 \mathrm{~d}$ of incubation $\left(37^{\circ} \mathrm{C}, 5 \% \mathrm{CO}_{2}\right), 1 \mu \mathrm{Ci}$ of $\left[{ }^{3} \mathrm{H}\right]$ thymidine per well $(6.7 \mathrm{Ci} / \mathrm{mM}$; New England Nuclear Corp., Boston, MA) was added and the cells harvested $4.5 \mathrm{~h}$ later. Incorporation of $\left[{ }^{3} \mathrm{H}\right]$ thymidine was detected by liquid scintillation and the data are presented as mean and standard deviation of the counts per minute of triplicate samples.

$I L-2$. Peripheral blood mononuclear cells from the study patients were adjusted to a concentration of $3 \times 10^{6} / \mathrm{ml}$ and stimulated with 20 $\mu \mathrm{g}$ of leishmania antigen. After $24 \mathrm{~h}$ the supernatants were harvested, filtered (Millipore, $0.45 \mu \mathrm{m}$ ), and stored at $-20^{\circ} \mathrm{C}$. IL-2 was measured using IL-2-dependent CTLL-2 cells (9). These cells were incubated with different dilutions of supernatant and the uptake of $\left[{ }^{3} \mathrm{H}\right]$ thymidine was determined after $24 \mathrm{~h}$ of incubation. The degree of CTLL-2 cell stimulation produced by supernatants was compared with that obtained using an IL-2 standard generated by concanavalin-A (Con A)-stimulated FS6 14.13 hybridoma cells, as previously described (10).

Gamma interferon. The same supernatants used for IL-2 measurement were used for determination of gamma interferon levels. The assay was performed by Dr. Michael E. Wiebe (New York Blood Center, New York), using a cytopathic effect inhibition assay with vesicular stomatitis 
virus in WISH cells (11). Antiviral activity was measured against a laboratory gamma interferon standard and is expressed as international units per milliliter (12).

Lymphocyte subpopulation. To determine the percentage of $\mathrm{T}$ cells and $T$ cell subsets, the mononuclear cells obtained from peripheral blood were depleted of macrophages by incubation of $8 \times 10^{6}$ cells in $6 \mathrm{ml}$ of RPMI, supplemented with $20 \%$ fetal calf serum at $37^{\circ} \mathrm{C}$ for $1 \mathrm{~h}$ on plastic. $\mathrm{T}$ cells were identified by the ability of these cells to bind three or more sheep erythrocytes (13). $\mathrm{OKT}_{4}^{+}$and $\mathrm{OKT}_{8}^{+}$cells were identified by indirect immunofluorescence using specific monoclonal antibodies (Anti-OKT and anti-OKT 8 ) (Ortho Diagnostic Systems, Inc., Raritan, NJ) and a fluorescinated goat anti-mouse immunoglobulin (14).

\section{Results}

Table I shows lymphocyte transformation responses to leishmania antigen and gamma interferon production by lymphocytes from eight patients with active VL, six patients with either mucosal or cutaneous leishmaniasis, and four healthy uninfected controls. As noted previously (3), proliferation responses to leishmania antigen during active visceral disease are markedly suppressed and do not exceed the responses of cells cultured without antigen or that of cells from healthy controls cultured with antigen. In contrast, the patients with mucocutaneous disease showed a good proliferative response to leishmania antigen (15). Gamma interferon levels were significantly lower in supernatants of lymphocytes from eight VL patients and equal to levels from unstimulated cells or cells from uninfected controls. Mucocutaneous patients showed high gamma interferon production under identical conditions. No significant differences were found in gamma interferon levels produced by phytohemagglutinin-stimulated cells in the three groups.

In addition, IL-2 levels in antigen-stimulated cells from the four active VL patients tested were found to be significantly lower $(433 \pm 370 \mathrm{cpm})$, when compared with levels obtained from antigen-stimulated cells from mucocutaneous leishmaniasis patients $(9,465 \pm 8,174)$. Phytohemagglutinin-stimulated cells from individuals in the three groups did not differ significantly in IL2 production ( $\mathrm{VL}, 9,523 \pm 1,071$; mucocutaneous leishmaniasis, $18,488 \pm 12,926$; healthy subjects, $9,380 \pm 8,325)$. The number of $\mathrm{OKT}_{4}^{+}$and $\mathrm{OKT}_{8}^{+}$cells was determined in the peripheral blood of four VL patients. One patient had a decreased number of T cells (less than the mean $\pm 2 \mathrm{SD}$ of controls, $2,310 \pm 543 \mathrm{~mm}^{3}$ ). The number of $\mathrm{OKT}_{4}^{+}$cells ranged from 458 to $1,746 \mathrm{~mm}^{3}$, and $\mathrm{OKT}_{8}^{+}$cells ranged from 427 to $1,100 \mathrm{~mm}^{3}$. The $\mathrm{OKT}_{4} / \mathrm{OKT}_{8}$ ratio was $1.5 \pm 0.8$, which is comparable with $2.3 \pm 0.4$ in controls (four healthy subjects).

To evaluate the change in gamma interferon and IL-2 levels associated with recovery from active VL, we studied three patients both before and after antimony therapy. Table II shows the data obtained from these patients. Proliferative responses were absent before therapy, but after therapy a mean proliferation response of $13,831 \mathrm{cpm}$ was observed. Gamma interferon levels also increased from $11 \pm 2 \mathrm{U} / \mathrm{ml}$ to a mean of $172 \mathrm{U} / \mathrm{ml}$ after treatment. IL-2 was present in significant amounts in $24-\mathrm{h}$ lymphocyte supernatants only after therapy.

\section{Discussion}

It is apparent that an important aspect of VL is a decrease in the ability of lymphocytes to respond to leishmania antigen by proliferation $(3,16,17)$ or by lymphokine production. There is not a generalized suppression of lymphocyte function since cells from VL patients responded normally in proliferation and in lymphokine production when stimulated with a lymphocyte mitogen. Recovery from active disease was associated with a lymphocyte response to leishmania antigen and production of lymphokines.

Lymphocytes from patients with active VL did not produce either IL-2 or gamma interferon when stimulated with leishmania antigen. IL-2 is important in mediating several lymphocyte functions $(18,19)$ and gamma interferon has been demonstrated to be the lymphokine that activates macrophages to kill leishmania intracellularly (20). The finding that lymphocytes from patients with active VL are unable to produce these lymphokines in response to specific antigen allows us to focus on what may be the major site of immune dysfunction during this disease.

$\mathrm{VL}$ is a complex disease associated with many features that could cause immunosuppression. For example, immune complexes are present $(5,21)$ and these have been associated with immune dysfunction in other diseases. We have found that sera from patients with active VL suppress mitogen-induced lymphocyte proliferation of normal cells (4). Further, there is a depletion of lymphocytes in T cell-dependent areas of the spleen and lymph nodes of VL patients (22). In spite of these recognized abnormalities, it remains unknown why there is antigen-specific unresponsiveness, manifested by the inability of lymphocytes to proliferate and produce lymphokine during active VL.

Table I. Lymphocyte Transformation and Gamma Interferon Production by Cells from Patients with Visceral or Mucocutaneous Leishmaniasis*

\begin{tabular}{|c|c|c|c|c|c|}
\hline \multirow[b]{2}{*}{ Groups } & \multicolumn{2}{|c|}{$\left[{ }^{3} \mathrm{H}\right]$ Thymidine uptake } & \multicolumn{3}{|l|}{ Gamma interferon } \\
\hline & Medium & $\begin{array}{l}\text { Leishmania } \\
\text { antigen }\end{array}$ & Medium & PHA & Leishmania antigen (range) \\
\hline & $c p m($ mean $\pm S D)$ & $c p m(m e a n \pm S D)$ & $U / m l(m e a n \pm S D)$ & $U / m l(m e a n \pm S D)$ & $U / m l(m e a n \pm S D)$ \\
\hline 1. Visceral leishmaniasis $¥(n=8)$ & $470 \pm 118$ & $776 \pm 26$ & $8 \pm 8$ & $222 \pm 95$ & $15 \pm 8 \quad(10-28)$ \\
\hline 2. Mucocutaneous leishmaniasis $(n=6)$ & $437 \pm 210$ & $26,582 \pm 3,913$ & $13 \pm 9$ & $306 \pm 244$ & $652 \pm 720(126-1,995)$ \\
\hline 3. Controls $(n=4)$ & $367 \pm 25$ & $568 \pm 114$ & $10 \pm 8$ & $225 \pm 54$ & $9 \pm 8 \quad(2-16)$ \\
\hline
\end{tabular}

* Group 1 vs. 3 , NS at all points; group 2 vs. $1,3, P<0.01$ for $\left[{ }^{3} \mathrm{H}\right]$ thymidine uptake using leishmania antigen; $P<0.01$ for gamma interferon levels using leishmania antigen. All other points, group 2 vs. 1,3 , NS. $¥$ The patients ranged from 2 to $31 \mathrm{yr}$ (mean, $10 \mathrm{yr}$ ) and were symptomatic for 2-20 mo (mean, $5.5 \mathrm{mo}$ ) before study. 
Table II. Chemotherapy Restores the Capacity of Lymphocytes from VL Patients to Generate Gamma Interferon, Produce IL-2, and to Proliferate when Stimulated by Leishmania Antigen

\begin{tabular}{|c|c|c|c|c|c|c|c|c|}
\hline \multirow[b]{3}{*}{ Patient no. } & \multicolumn{4}{|c|}{ Incorporation of $\left[{ }^{3} \mathrm{H}\right]$ thymidine gamma interferon ${ }^{*}$} & \multicolumn{4}{|l|}{ IL-2 $\ddagger$} \\
\hline & \multirow[b]{2}{*}{$\begin{array}{l}\text { Before } \\
\text { treatment }\end{array}$} & \multirow[b]{2}{*}{ After treatment } & \multirow[b]{2}{*}{$\begin{array}{l}\text { Before } \\
\text { treatment }\end{array}$} & \multirow[b]{2}{*}{$\begin{array}{l}\text { After } \\
\text { treatment }\end{array}$} & \multicolumn{2}{|c|}{ Before treatment } & \multicolumn{2}{|l|}{ After treatment } \\
\hline & & & & & $1: 4$ & $1: 8$ & $1: 4$ & $1: 8$ \\
\hline & cpm (mean $\pm S D)$ & cpm (mean $\pm S D)$ & $U / m l$ & $U / m l$ & & & & \\
\hline 1 & $514 \pm 34$ & $2,469 \pm 418$ & 13 & 158 & 2,000 & $980 \pm 50$ & $10,080 \pm 297$ & $7,435 \pm 5$ \\
\hline 2 & $140 \pm 25$ & $6,470 \pm 865$ & 11 & 159 & $575 \pm 176$ & $270 \pm 50$ & $27,755 \pm 1689$ & $22,015 \pm 37$ \\
\hline 3 & $277 \pm 51$ & $32,555 \pm 2,484$ & 9 & 200 & ND & ND & ND & ND \\
\hline Mean values & 310 & 13,831 & 11 & 172 & 1,288 & 625 & 18,918 & 14,725 \\
\hline
\end{tabular}

* In addition to antigen stimulation, cells were also stimulated with pokeweed mitogen (final concentration, 1:100), as positive control for cell proliferation. Mean values: before treatment, 15,359 $\pm 12,596$; after treatment, 18,676 $\pm 3,815$. $¥$ IL-2 standard gave a proliferation value of $21,525 \pm 983 \mathrm{cpm}$ at 1:8 dilution. $\S$ The interval between the before and after treatment studies was 6-9 wk.

It is of interest that other infectious diseases that compromise lymphocyte function and that are associated with increased susceptibility to infection (i.e., acquired immune deficiency syndrome [AIDS]) also are characterized by suppressed production of both gamma interferon and IL-2 $(23,24)$. However, the mechanism of the altered production of lymphokines in AIDS and $\mathrm{VL}$ is probably different. For example, the inability to produce lymphokine is antigen specific in $\mathrm{VL}$, and $\mathrm{OKT}_{4}^{+}$numbers are preserved during leishmaniasis, while nonspecific lymphocyte suppression and decreased numbers of $\mathrm{OKT}_{4}^{+}$cells occur in AIDS. Low gamma interferon production has also been reported in lepromatous leprosy (25). This decreased lymphokine production appears not to be antigen specific since low gamma interferon levels were observed in Con A-stimulated cultures, it was not restored by therapy, and an increase in tissue $\mathrm{OKT}_{8}^{+}$ cells was recorded. Whether these results, which differ from those observed in the patients with VL reported here, represent differences in technique of study or differences between the two diseases needs to be determined. In one patient with early cutaneous leishmaniasis, both proliferation of lymphocytes and gamma interferon production were low, and restoration occurred either with natural progression of the immune response or drug therapy (26).

The pathogenesis of VL is not understood. It is clear that active $\mathrm{VL}$ is but one part of the disease spectrum of $L$. donovani infection since most of the infected subjects do not develop disease $(7,27)$. In an area endemic for VL, we have also observed that early in the infection some patients have the ability to respond to leishmania antigen by lymphocyte blastogenesis and intradermal skin test, and some do not (personal observation). The mechanisms that determine progression of the infection are unknown. It is clear that a depressed cell-mediated immune response is a hallmark of the disease, and it is possible that susceptibility to the development of clinical VL is related to an inability to generate IL-2 and gamma interferon to leishmania antigens during the infection.

\section{Acknowledgments}

We are grateful to Olivia Bacellar and Jill Inverso for their excellent technical assistance, Dr. Michael Wiebe for determination of gamma interferon, and Rosa Dalforno for typing this manuscript.

This work was supported by National Institutes of Health grant AI 16282 and the National Research Council of Brazil (CNPq).

\section{References}

1. Andrade, T. M., R. Teixeira, J. A. F. Andrade, C. Pereira, and E. M. Carvalho. 1982. Hipersensibilidade do tipo retardado na leishmaniose visceral. Rev. Inst. Med. Trop. Sao Paulo. 24:298-302.

2. Manson-Bahr, P. E. C. 1961. Immunity in Kala-azar. Trans. Roy. Soc. Trop. Med. Hyg. 55:550-555.

3. Carvalho, E. M., R. S. Teixeira, and W. D. Johnson, Jr. 1981. Cell mediated immunity in American visceral leishmaniasis: reversible immunosuppression during acute infection. Infect. Immun. 33:498-502.

4. Carvalho, E. M., and O. Bacellar. 1983. Lymphocyte reactivity to mitogens in American visceral leishmaniasis. Bras. J. Med. Biol. Res. 16:35-41.

5. Galvão-Castro, B., J. A. Sá Ferreira, K. F. Marzochi, M. C. Marzochi, S. G. Coutinho, and P. H. Lambert. 1984. Polyclonal B-cell activation, circulating immune complexes, and autoimmunity in human visceral leishmaniasis. Clin. Exp. Immunol. 56:58-66.

6. Guerreiro, J., S. Ribeiro, E. M. Carvalho, R. Badaró, and H. Rocha. 1985. Infecção bacteriana em pacientes portadores de leishmaniose visceral. Mem. Inst. Oswaldo Cruz Rio de J. In press.

7. Badaró, R., S. G. Reed, A. Barral, G. Orge, and T. C. Jones. 1985. Evaluation of the micro enzyme linked immunosorbent assay (ELISA) for antibodies to American visceral leishmaniasis: standardization of parasite antigen to detect infection-specific responses. Am. J. Trop. Med. Hyg. In press.

8. Lowry, O. H., N. G. Rosebrough, A. L. Farr, and R. J. Randall. 1951. Protein measurement with the folin phenol reagent. J. Biol. Chem. 193:265-275.

9. Gillis, S., M. M. Ferm, W. Ou, and K. A. Smith. 1978. T cell growth factor: parameters of production and a quantitative microassay for activity. J. Immunol. 120:2027-2032.

10. Reed, S. G., J. A. Inverso, and S. B. Roters. 1984. Suppressed antibody responses to sheep erythrocytes in mice with chronic Trypanasoma cruzi infections are restored with interleukin 2. J. Immunol: 133: 3333-3337.

11. Stewart, W. D. 1981. The Interferon System. Springer-Verlag, New York. Second ed. 13-24.

12. Rubin, B. Y., A. H. Bartal, S. L. Anderson, S. K. Millet, Y. Hirshaut, and C. Feit. 1983. The anticellular and protein-inducing activities of human gamma interferon preparations are mediated by the interferon. J. Immunol. 130:1019-1020.

13. World Health Organization IARC Workshop. 1974. Special technical report. Identification, enumeration and isolation of $B$ and $T$ lymphocytes from human peripheral blood. Scand. J. Immunol. 3:521532.

14. Reinherz, E. L., P. C. Kung, G. Goldstein, and S. F. Schlossman. 1979. Separation of functional subsets of human T cells by a monoclonal antibody. Proc. Natl. Acad. Sci. USA. 76:4061-4065. 
15. Castes, M., A. Agnelli, O. Verde, and J. Rondon. 1983. Characterization of the cellular immune response in American cutaneous leishmaniasis. Clin. Immunol. Immunopathol. 27:176-186.

16. Haldar, J. P., S. Chose, K. C. Saha, and A. C. Ghose. 1983. Cellmediated immune response in Indian kala-azar and post kala-azar dermal leishmaniasis. Infect. Immun. 42:702-707.

17. Ho, M., D. K. Koech, D. W. Iha, and A. D. M. Bryceson. 1983. Immunosuppression in Kenya visceral leishmaniasis. Clin. Exp. Immunol. 51:207-214.

18. Farrar, J. J., J. Fuller-Farrar, P. L. Simon, M. L. Hilfiker, B. M. Stadler, and W. L. Farrar. 1980. Thymoma production of T cell growth factor (interleukin 2). J. Immunol. 125:2555-2558.

19. Smith, K. A. 1984. Interleukin 2. Annu. Rev. Immunol. 2:319333.

20. Murray, H. W., B. Rubin, and C. D. Rothermel. 1983. Killing of intracellular Leishmania donovani by lymphokine-stimulated human mononuclear phagocytes. Evidence that interferon gamma is the activating lymphokine. J. Clin. Invest. 72:1506-1510.

21. Carvalho, E. M., B. S. Andrews, R. Martinelli, M. Dutra, and H. Rocha. 1983. Circulating immune complexes and rheumatoid factor in schistosomiasis and visceral leishmaniasis. Am. J. Trop. Med. Hyg. 32:61-68.
22. Veress, B., A. Omer, A. A. Satir, and A. M. El Hassan. 1977. Morphology of the spleen and lymph nodes in fatal visceral leishmaniasis. Immunology. 33:605-610.

23. Murray, H. W., B. Y. Rubin, H. Masur, and R. B. Roberts. 1984. Impaired production of lymphokines and immune (gamma) interferon in the acquired immunodeficiency syndrome. $N$. Engl. J. Med. 310:883889.

24. Lawrence, J., A. B. Gottlieb, and H. G. Kunkel. 1983. Soluble suppressor factors in patients with acquired immunodeficiency syndrome and its prodome: elaboration in vitro by $\mathrm{T}$ lymphocyte-adherent cell interactions. J. Clin. Invest. 72:2072-2081.

25. Nogueira, N., G. Kaplan, E. Levy, E. N. Sarno, P. Kushner, A. Granelli-Piperno, L. Vieira, V. C. Gould, W. Levis, R. Steinman, Y. K. Yip, and Z. A. Cohn. 1983. Defective gamma interferon production in leprosy: reversal with antigen and interleukin 2.J. Exp. Med. 158:21652170.

26. Murray, H. W., B. Y. Rubin, S. Carriero, and A. M. Acosta. 1984. Reversible defect in antigen-induced lymphokine and gamma interferon generation in cutaneous leishmaniasis. J. Immunol. 133:22502254.

27. Ho, M., J. Leeuwenburg, G. Mbugua, A. Wachi, and A. Voller. 1983. An enzyme-linked immunosorbent assay (ELISA) for field diagnosis of visceral leishmaniasis. Am. J. Trop. Med. Hyg. 32:943-946. 